\title{
Positron emission and single-photon emission imaging: synergy rather than competition
}

\author{
Giuliano Mariani • H. William Strauss
}

Published online: 12 March 2011

(C) Springer-Verlag 2011

Some proponents of positron imaging have suggested that single-photon imaging procedures would be totally replaced by PET imaging [1-3]. Proponents and opponents of such a scenario have each argued about the relative merits of the two modalities, and the issues involved in the clinician's choice in different health-care systems [4-7]. These issues include availability of a PET alternative to a planar/SPECT procedure, regulatory approval of the radiopharmaceuticals and procedures, cost/reimbursement issues, and radiation protection for personnel.

The growth of PET examinations in recent years has been impressive, although at different rates in different parts of the world. In a country where diffusion of clinical PET started early, such as the USA, the number of PET examinations increased by about $35 \%$ in the period 2005-2008, although with a declining computed annual growth rate (CAGR) from $14.5 \%$ in 2006 to $4.4 \%$ in 2008 (source: IMV, Des Plaines, IL). Where diffusion of clinical PET started more recently, as in Western Europe, the number of PET procedures increased by $82 \%$ with a smaller decline in CAGR, from $29 \%$ to $21 \%$, over the same period (sources: Medical Options, London, UK; European Association of Nuclear Medicine). Contrary to what one would expect for PET gradually replacing single-photon imaging, this increase in PET has not been mirrored by a corresponding decrease in planar/SPECT examinations.

\footnotetext{
G. Mariani $(\square)$

Regional Center of Nuclear Medicine,

University of Pisa Medical School,

Via Roma 67,

I-56100 Pisa, Italy

e-mail: g.mariani@med.unipi.it

H. W. Strauss

Nuclear Medicine Service, Department of Radiology,

Memorial Sloan-Kettering Cancer Center,

New York, NY, USA
}

This confirms the overall vitality of functional imaging with nuclear medicine. In fact, the only single-photon procedure that has declined consistently (by $7-8 \%$ ) is ventilation/perfusion lung scanning for pulmonary embolism, clearly due to competition from multidetector spiral-CT pulmonary angiography [8] and not from PET. The number of all other planar/SPECT procedures has remained stable in Europe or has actually increased, either moderately $(+2 \%$ for brain and myocardial perfusion), or markedly: $+17.4 \%$ for infection/inflammation imaging, $+17.5 \%$ for sentinel node scintigraphy, $+42.1 \%$ for brain receptor imaging.

In this pattern one can see the effects of an ongoing crossfertilization already in place between the two imaging methodologies. Transfer of PET/CT cross-sectional imaging expertise to SPECT/CT has clearly revitalized the latter for both preclinical and clinical applications [9-11]. The advantages include not only improved topographic localization compared with radionuclide-based transmission/emission imaging, but also more accurate attenuation correction making quantitation possible also with SPECT [12]. Therefore, future scenarios for nuclear medicine are taking on new perspectives, especially considering that the shortage of molybdenum-99 [13] seems now to be solved [14]. This change in perspective is reflected by a recent surge in new SPECT/CT installations; in the third quarter of 2010 a major manufacturer has seen revenues from sales of SPECT installations exceed those from PET installations for the first time in years (personal communication), a large proportion of which are multimodality SPECT/CT devices. Likewise, transfer of conventional SPECT studies to PET/CT is being explored with a synergistic flow in the opposite direction with questions such as: "How might we image infection and/or inflammation with PET/CT?" and "What would a high resolution ventilation/perfusion PET/CT lung scan look like?".

PET and SPECT are synergistic for introducing new radiopharmaceuticals for both preclinical and clinical 
purposes, as new agents are now developed in parallel for positron and for single-photon emitters [15-20]. A common approach to minimizing radiation dose to patients while enhancing image quality is also being adopted for PET and SPECT [21]. An example of this can be seen in the recent development of solid-state detectors for cardiac imaging, where images recorded with lower injected doses have diagnostic quality equal to that obtained with higher doses and conventional gamma camera SPECT imaging [22].

Thus, the real issue is not which radionuclide imaging procedure will prevail, but rather how to make the best possible use of what is available now and for the foreseeable mid-term future. Besides the uncertainties surrounding approval and wide availability of new radiopharmaceuticals, the overall costs to the health-care systems that a total shift from planar/SPECT to PET imaging would imply must be considered. In this regard, although until recently we had assumed that PET radiotracers would always be more expensive than the single-photon tracers based on ${ }^{99 \mathrm{~m}} \mathrm{Tc}$ labelling, recent events (such as the unexpected worldwide molybdenum-99 shortage) may cause us to question this received wisdom.

This point is well illustrated by the case of PET with ${ }^{18} \mathrm{~F}$ fluoride advocated to replace ${ }^{99 \mathrm{~m}} \mathrm{Tc}-\mathrm{MDP}$ bone scintigraphy [23]. In Europe about 2.5 million ${ }^{99 \mathrm{~m}} \mathrm{Tc}-\mathrm{MDP}$ bone scans are currently performed per year. Replacing those procedures with sodium ${ }^{18} \mathrm{~F}$-fluoride PET/CT would result in a sudden increase in the current cost for health-care by a factor 25 $40 \%$. Yet, the impact of such a shift on patient management has still to be determined. Moreover, additional health-care costs would result from installing the PET/CT tomographs required to accommodate the large number of new PET procedures (by a factor of $>10$ ). Conversely, the greater the utilization of the PET/CT scanner, the less expensive (per patient) each examination would become.

In conclusion, in this time of rapid changes in health-care delivery [24], we need to build on the strengths of radionuclide imaging by both positron and single photon techniques. This is not a time for internecine warfare lest we bring a plague on both our houses. We need to commence an era of constructive collaboration, to ensure prosperity and growth of the entire nuclear medicine community.

\section{Conflicts of interest None.}

\section{References}

1. Alavi A, Basu S. Planar and SPECT imaging in the era of PET and PET-CT: can it survive the test of time? Eur J Nucl Med Mol Imaging. 2008;35:1554-9.
2. Basu S, Alavi A. Revolutionary impact of PET and PET-CT on the day-to-day practice of medicine and its great potential for improving future health care. Nucl Med Rev Cent East Eur. 2009;12:1-13.

3. Segall GM. Are two photons better than one? PET COE Newsletter. 2010;7:1-3.

4. Jansen FP, Vanderheyden JL. The future of SPECT in a time of PET. Nucl Med Biol. 2007;34:733-5.

5. Mariani G, Bruselli L, Duatti A. Is PET always an advantage versus planar and SPECT imaging? Eur J Nucl Med Mol Imaging. 2008;35:1560-5.

6. Beller GA. Will cardiac positron emission tomography ultimately replace SPECT for myocardial perfusion imaging? J Nucl Cardiol. 2009; 16:841-3.

7. Gholamrezanehad A, Mirpour S, Mariani G. Future of nuclear medicine: SPECT versus PET. J Nucl Med. 2009;50:16N-18N.

8. Reid JH, Coche EE, Inoue T, Kim EE, Dondi M, Watanabe N, et al. Is the lung scan alive and well? Facts and controversies in defining the role of lung scintigraphy for the diagnosis of pulmonary thromboembolism in the era of multidetector CT. Eur J Nucl Med Mol Imaging. 2009;36:505-21.

9. Franc BL, Acton PD, Mari C, Hasegawa BH. Small-animal SPECT and SPECT/CT: important tools for preclinical investigation. J Nucl Med. 2008;49:1651-63.

10. Buck AK, Nekolla SG, Ziegler SI, et al. SPECT/CT. J Nucl Med. 2008;49:1305-19.

11. Mariani G, Bruselli L, Kuwert T, et al. A review on the clinical uses of SPECT/CT. Eur J Nucl Med Mol Imaging. 2010;37:195985.

12. Willowson K, Bailey DL, Baldock C. Quantitative SPECT using CT-derived corrections. Phys Med Biol. 2008;53:3099-112.

13. Gould P. Medical isotope shortage reaches crisis level. Nature. 2009;460(7253):312-3.

14. Dadparvar S. Domestic isotope producers selected. J Nucl Med. 2010;51:22N-26N.

15. de Kemp RA, Epstein FH, Catana C, Tsui BM, Ritman EL. Smallanimal molecular imaging methods. J Nucl Med. 2010;51 Suppl $1: 18 \mathrm{~S}-32 \mathrm{~S}$.

16. Vanderheyden JL. The use of imaging in preclinical drug development. Q J Nucl Med Mol Imaging. 2009;53:374-81.

17. Sobrio F, Gilbert G, Perrio C, Barré L, Debruyne D. PET and SPECT imaging of the NMDA receptor system: an overview of radiotracer development. Mini Rev Med Chem. 2010;10:870-86.

18. Wängler C, Schirrmacher R, Bartenstein P, Wängler B. Click-chemistry reactions in radiopharmaceutical chemistry: fast \& easy introduction of radiolabels into biomolecules for in vivo imaging. Curr Med Chem. 2010;17:1092-116.

19. Holland JP, Williamson MJ, Lewis JS. Unconventional nuclides for radiopharmaceuticals. Mol Imaging. 2010;9:1-20.

20. Valliant JF. A bridge not too far: linking disciplines through molecular imaging probes. J Nucl Med. 2010;51:1258-68.

21. Hoeschen C, Mattsson S, Cantone MC, et al. Minimising activity and dose with enhanced image quality by radiopharmaceutical administrations. Radiat Prot Dosim. 2010;139:250-3.

22. Bocher M, Blevis IM, Tsukerman L, Shrem Y, Kovalski G, Volokh L. A fast cardiac gamma camera with dynamic SPECT capabilities: design, system validation and future potential. Eur J Nucl Med Mol Imaging. 2010;37:1887-902.

23. Segall G, Delbeke D, Stabin MG, Even-Sapir E, Fair J, Sajdak R, et al. SNM practice guideline for sodium ${ }^{18} \mathrm{~F}$-fluoride PET/CT bone scans 1.0. http://interactive.snm.org/docs/Procedure_Outline NaF PETV1.0.pdf

24. Hicks RJ, Borland J. Are health economics making us sick? J Nucl Med. 2010;51:1665-7. 